\title{
Geoportal Turístico de una Región Rural como Medio de Difusión de su Oferta y Recursos. Caso de Estudio: Extremadura
}

\section{Tourist Geoportal of a Rural Region as a Means of Disseminating its offer and Resources. Case Study: Extremadura}

\author{
Ángela Engelmo-Moriche \\ angelaengelmo@unex.es@0000-0001-5330-2203 \\ Ana Nieto-Masot \\ ananieto@unex.es@0000-0001-9301-8637 \\ Ana Isabel Horcajo-Romo \\ anhorcajo@alumnos.unex.es@0000-0002-6811-3445 \\ Gema Cárdenas-Alonso \\ gemacardenas@unex.es @ 0000-0002-4977-8599 \\ Departamento Arte y Ciencias del Territorio.
}

Facultad de Filosofía y Letras. Universidad de Extremadura. Campus Universitario s/n. 10071-Cáceres.

\section{INFO ARTÍCULO}

Recibido: 08-06-2020

Revisado: 18-01-2021

Aceptado: 19-01-2021

\section{PALABRAS CLAVE}

\section{ArcGIS Online}

Bases de datos

Extremadura

Geoportal

Oferta turística

Recursos turísticos

\section{KEYWORDS}

ArcGIS Online

Databases

Extremadura

Feoportal

Tourist offer

Tourist resources

\begin{abstract}
RESUMEN
El turismo en Extremadura se ha visto favorecido, durante las últimas décadas, debido a nuevas tendencias (turismo rural, turismo gastronómico, etc.) que han aumentado el número de visitantes que eligen la región como destino de vacaciones debido a su amplia gama de recursos y equipamientos. El objetivo de este trabajo es elaborar una base de datos digital que permita dar a conocer la oferta y los recursos turísticos de la región, adaptándola a las demandas actuales del mercado, mediante la creación de un SIG Web o Geoportal. Para el diseño del mismo se empleó la herramienta ArcGIS Online, que ofrece una experiencia gratuita y que da como resultado un visor intuitivo y adecuado a las nuevas tecnologías.
\end{abstract}

\begin{abstract}
During the last decades, tourism in Extremadura has been favoured due to new trends (rural tourism, gastronomic tourism...), which have increased the number of visitors who choose the region as a holiday destination due to its wide range of resources and facilities. In this study, the objective is to create a digital database that will make the region's tourism offer and resources known, adapting it to current market demands, by creating a Web GIS or Geoportal. For the design of the Geoportal, the ArcGIS Online tool was used, which offers a free experience and results in an intuitive viewer suitable for new technology.
\end{abstract}




\section{INTRODUCCIÓN}

En España, la actividad turística no comienza a cobrar relevancia hasta la segunda mitad del siglo XX, cuando la fase desarrollista del régimen franquista permite la entrada de divisas extranjeras. En esos momentos, el turismo se convierte en uno de los sectores económicos más potenciados desde el gobierno, el denominado boom turístico (Vizcaíno, 2015), bajo el eslogan Spain is different. Sin embargo, este turismo era exclusivista y solo se contemplaba en las zonas de costa en detrimento de las regiones de interior y más ruralizadas, a excepción de Madrid y algunos otros destinos urbanos interiores, provocando importantes desigualdades. A finales de los años 80, la masificación del litoral español (Cánoves et al., 2005; Godfrey et al., 2000; Sánchez et al., 2001) incentiva la búsqueda de nuevas tipologías turísticas que satisficieran las necesidades de los habitantes de las urbes, que demandaban destinos menos masificados donde descansar, disfrutar de la naturaleza y desconectar de las grandes ciudades. Estos cambios en los paradigmas turísticos posibilitaron el desarrollo de diversas tipologías en regiones anteriormente desligadas de dicha actividad: el turismo rural (que previamente se había extendido en países como Francia, Reino Unido o Austria), el agroturismo, el turismo de naturaleza, el turismo patrimonial o el turismo gastronómico.

En este contexto, Extremadura, zona de estudio, lleva más de dos décadas fomentando el desarrollo del turismo mediante diferentes políticas de actuación, como los Planes Estratégicos diseñados por la Junta de Extremadura, las ayudas del Programa Operativo Proder de ámbito nacional o las subvenciones europeas cofinanciadas por la Iniciativa Leader (Cárdenas et al., 2017; Nieto et al., 2018). Gracias a estas ayudas y al fomento de las inversiones privadas se ha conseguido que la actividad se convierta en una fuente de ingresos importante para las rentas extremeñas (López-Guzmán et al., 2014), siendo en 2018 el sector económico que más creció en la región (Nieto et al., 2020a) con 27.000 empleos y 922 nuevos puestos de trabajo generados (INE, 2018b), aportando el 5\% del PIB regional. Sin embargo, pese al esfuerzo por llevar al turismo a una posición relevante en la economía regional, su situación de partida conlleva décadas de retraso que se arrastran hasta la actualidad, debido, no solo al peso de la agricultura, que domina en buena parte de la región, o a los problemas de accesibilidad, especialmente reseñable en zonas con una orografía complicada o fronterizas; sino a que el turismo sigue siendo muy estacional, ligado principalmente a los fines de semana y a las vacaciones estivales con un estancia media de 1,84 días (Observatorio de Turismo, 2018), un dato muy inferior a la media nacional de 3,23 días (INE, Instituto Nacional de Estadística, 2018a). Por ello, la aportación al PIB extremeño es bastante inferior si se compara con la media nacional del 11,7\% en 2018 (Nieto et al., 2020a).

El caso de Extremadura no es exclusivo de España, Comunidades Autónomas (CCAA a partir de ahora) como Castilla-La Mancha (Pillet, 2016), Castilla y León (Rico, 2005), Aragón (Sanagustin-Fons et al., 2018) o Andalucía (Blancas et al., 2011; Sarrión-Gavilán et al., 2015) también están experimentando un importante desarrollo en el turismo rural, fomentadas por ayudas europeas como el Método Leader (Nieto et al., 2017; Perez et al.,2005), ayudas nacionales como la Iniciativa Proder (Castellano-Álvarez et al., 2019) o ayudas de las administraciones regionales (Laguna et al.,2007; Millán et al., 1999). Resulta irrefutable el efecto positivo que tiene el desarrollo del turismo rural en regiones como Extremadura, tanto desde una perspectiva socioeconómica (alternativa y complementaria a la producción agrícola a modo de contribuir como nueva fuente de ingresos y empleo), como desde una perspectiva sociocultural (mantenimiento de la población en áreas rurales y contribución a la conservación y a la protección de los recursos y del espacio natural). Por ello, es necesario destacar la importancia que puede tener la actividad turística y, en concreto, algunas de sus tipologías, para la nueva funcionalidad del mundo rural, sobre todo en regiones donde la tradición agraria ha tenido históricamente un gran peso (Cánoves et al., 2004) permitiendo que los recursos naturales conservados presenten una gran calidad.

A lo anterior hay que unir los profundos cambios que está experimentando la demanda turística, cada vez más exigente y sofisticada (García et al., 2003), imponiendo el desarrollo de un nuevo sistema de oferta coherente con las nuevas expectativas de los denominados como turistas 3.0. Esta nueva categoría de turistas demanda la introducción de las nuevas tecnologías en la planificación y en el desarrollo de sus viajes (Bastante, 2018), de forma que puedan conocer su destino incluso antes de su llegada. De esta manera, las 
nuevas Tecnologías de la Información y la Comunicación (TIC) se convierten en un factor de competencia y diversificación para los actores turísticos, tanto públicos como privados, gracias a las ventajas competitivas que ofrecen (Buhalis et al., 2013; Ivars et al., 2016; Sarmiento et al., 2019). Por un lado, permiten que las empresas optimicen su eficiencia y reduzcan los gastos, mejoren en la calidad de atención al cliente o el acceso al mercado global (Albacere et al.,2012; Reveiu, 2017) y, además, contribuye a mejorar la planificación de los viajeros con información detallada de los alojamientos, de las actividades a realizar en los destinos, localización de los recursos y equipamientos en tiempo real u opiniones y recomendaciones de otros usuarios a través de plataformas digitales como las web 2.0 (O'Reilly, 2007) (foros, blog, redes sociales, etc.), o las bases SIG web (geowebs o geoportales) (Elwood, 2009).

En los últimos años, los SIG web se han consolidado como una clave en cualquier proceso relacionado con la difusión de información turística (Buhalis, 2012; Koshkarev et al., 2008; Sigala et al., 2012; Yamashkin et al., 2019). Por ello, algunos organismos públicos han generado visores y geoportales que garanticen el acceso a la información (Hu et al.,2015; Ojeda et al.,2015), pudiendo destacar el visor turístico de las Islas Canarias (www.idecanarias.es/ o visor.grafcan.es/visorweb/) o el desarrollado por la Xunta de Galicia (http:// mapas.xunta.gal/portada) financiado por los Fondos FEDER. A nivel internacional, destacan geoportales como el generado por la Oficina Nacional de Turismo de China en España (www.turismochina.org/web/index.php), el geoportal elaborado por la Office de Tourisme de París (www.paris.fr/equipements) o el SIG web elaborado por una Iniciativa LEADER+ en Italia (Costantino et al.,2019) para la protección y gestión sostenible del patrimonio rural. No obstante, su utilidad no solo revierte en el ámbito de la difusión de la información turística, patrimonial y cultural, sino que es mucho más amplia: monitoreo de sistemas tecnológicos ( $\mathrm{Xu}$, 2015); gestión de los usos del suelo (Cegielska et al., 2018; Granell et al., 2017); prevención y reducción de desastres naturales (Giuliani et al., 2011); gestión del tráfico (Gunay et al., 2014); visores como estrategias para conseguir un desarrollo sostenible (Rodríguez et al., 2017; Tu et al., 2009), o visores como el del Ministerio de Agricultura, Alimentación y Medio Ambiente (MAPAMA) con información cartográfica de aridez, de agroturismo, medioambiental, etc. En el caso de la región de estudio, la Dirección General de Turismo de la Junta de Extremadura desarrolló un geoportal sencillo e intuitivo con una amplia base de datos; sin embargo, debido a la rápida evolución del sector, actualmente no se adapta a la demanda del mercado.

Reuniendo todos los aspectos citados, el presente trabajo pretende dar a conocer la oferta turística y los recursos patrimoniales y naturales al potencial turista de una región rural como Extremadura en un geoportal que sirva como punto de encuentro de información directa, intuitiva y actualizada creado por medio de softwares y herramientas (en este caso, ArcGis Online) gratuitas.

A continuación, se presenta la Sección 2 con el marco teórico; los materiales y métodos de este trabajo, así como el área de estudio, en la Sección 3; seguido de la Sección 4 en la que se muestran los resultados obtenidos; la Sección 5 con la discusión y, por último, la Sección 6, donde se exponen las conclusiones extraídas.

\section{MARCO TEÓRICO}

Entre los años 50 y 70 del pasado siglo se inicia la denominada Revolución Digital con la aparición de internet y de las TIC, pero habría que esperar unas cuantas décadas para que se produjese la universalización de su uso, puesto que, en sus inicios, los enormes costes tecnológicos limitaban su aplicación más extendida, limitándose el uso a universidades de prestigio internacional, entes gubernamentales y multinacionales de alta tecnología. Sería, principalmente, a partir de la década de los 90 cuando se produciría la democratización en su uso con la aparición de los primeros buscadores en línea, la puesta en marcha de plataformas publicitarias y la venta online. Internet resulta entonces un medio que mejora las oportunidades de venta de las empresas, siendo el turismo uno de los sectores que más se han beneficiado de la interacción en la compra de billetes, reservas y visitas virtuales (Anato, 2006). Estos avances han cambiado tanto las prácticas y estrategias comerciales como las estructuras de la industria (Porter, 2001).

La interacción entre la tecnología y el turismo en los últimos tiempos ha traído cambios fundamentales en la industria (Buhalis et al., 2008) y en la forma de percibirla por parte de los viajeros. Las TIC permiten a 
los viajeros acceder a la información confiable y precisa, así como realizar reservas en una fracción del tiempo evitando costes y molestias que requieren otros métodos convencionales (O'Conner, 1999), facilitando las necesidades de los consumidores. De esta forma, el turista (denominado turista 1.0 o turista tradicional) pasa de preparar sus viajes a través de agencias de viajes externas o de opiniones de familiares y amigos, así como mediante el uso de mapas físicos, a utilizar internet como medio para reservar sus viajes a través de diferentes plataformas digitales (turista 2.0). El turista 2.0 aparece unos años después de la denominada como crisis puntocom (Capel, 2010), en 2001, cuando diversas empresas vinculadas a internet quebraron. Debido a ello, aparece el concepto de Web 2.0. y comienzan a surgir plataformas que permiten una mayor interacción entre los usuarios (blogs y primeras plataformas sociales que sentarían las bases de las redes sociales que conocemos hoy en día). Con la llegada de los smartphones, la proliferación de sitios web que permiten tanto reservar viajes (vuelos, hoteles, transporte, etc.) como obtener opiniones de otros usuarios (Tripadvisor, Edreams, Kayak, etc.), el uso cada vez más extendido de aplicaciones mapas (por ejemplo, Google Maps) y la rápida expansión de las Redes Sociales (Facebook, Youtube, Twitter o Instagram) aparece el denominado como turista 3.0. Es un nuevo tipo de turista digital, hiperconectado y multicanal que solo utiliza internet para organizar su viaje (Bastante, 2018).

La rápida evolución que han tenido tanto las TIC como el turismo digital ha permitido la creación de diferentes plataformas digitales, como los geoportales, que intentan responder a las nuevas necesidades de los viajeros. El desarrollo de los geoportales con aplicación en el sector turístico se inicia aproximadamente en 1993 con sitios webs como MapQuest ó Mapblast, servidores online gratuitos que permitían calcular la ruta óptima entre dos lugares. De esta forma, los geoportales son vistos como plataformas que permiten visualizar información geográfica útil para cualquier tipo de usuario, que no necesitan la descarga de ninguna aplicación por parte de los usuarios y además por la existencia de software gratuitos que permiten la creación de dichos geoportales potencian que las administraciones o empresas los consideren como una forma de promoción del turismo con bajo coste de realización y de mantenimiento.

Son múltiples los geoportales o sitios web con información geográfica creados desde las administraciones públicas destinados a potenciar el sector turístico en su ámbito de actuación (local, provincial o regional). Ejemplo de ello lo encontramos en el visor turístico del Ayuntamiento de Peñíscola (www.peniscola.es/) encaminado a la presentación de información geográfica online con el objetivo de establecer una comunicación directa entre el turista y los recursos ofertados creados mediante ArcGIS Online de Esri y mapas de Google maps, que acumuló más de 40.000 visitas en sus primeros meses de publicación. También añadir el geoportal que acaba de presentar el Ayuntamiento de Valencia, https://geoportal.valencia.es/, con más de 600.000 puntos georreferenciados, con servicios de mapas y con información a tiempo real de la capacidad de los parkings y de las playas. Además, estos geoportales completan su información con las redes sociales donde acumulan más de 50.000 seguidores. Estos datos demuestran la importancia y la eficacia de los geoportales en el ámbito de las administraciones públicas como medio de difusión de diversos territorios.

\section{MATERIAL Y MÉTODOS}

\section{1. Área de estudio}

La región extremeña se localiza al oeste de España, limitando al este con Castilla-La Mancha, septentrionalmente con Castilla y León, al sur con Andalucía y el este con Portugal. Presenta un área de 40.000 Km², vertebrada por dos principales vías de comunicación, la A-5 dirección Madrid-Lisboa y la A-66 dirección Gijón-Sevilla; y aproximadamente 1 millón de habitantes (INE, 2019), repartidos en 388 municipios. Su densidad de población, 26 hab/km², es una de las más bajas a nivel nacional (Figura 1).

Históricamente, Extremadura se ha caracterizado por su situación periférica y limítrofe, especialmente por ser zona fronteriza con Portugal, influyendo en el desarrollo urbano de los pueblos aledaños con un legado patrimonial asociado a construcciones militares (Cayetano, 2010) y contribuyendo a que la zona no pudiese desarrollarse socioeconómicamente, actuando como factor de repulsión de la población. Del 


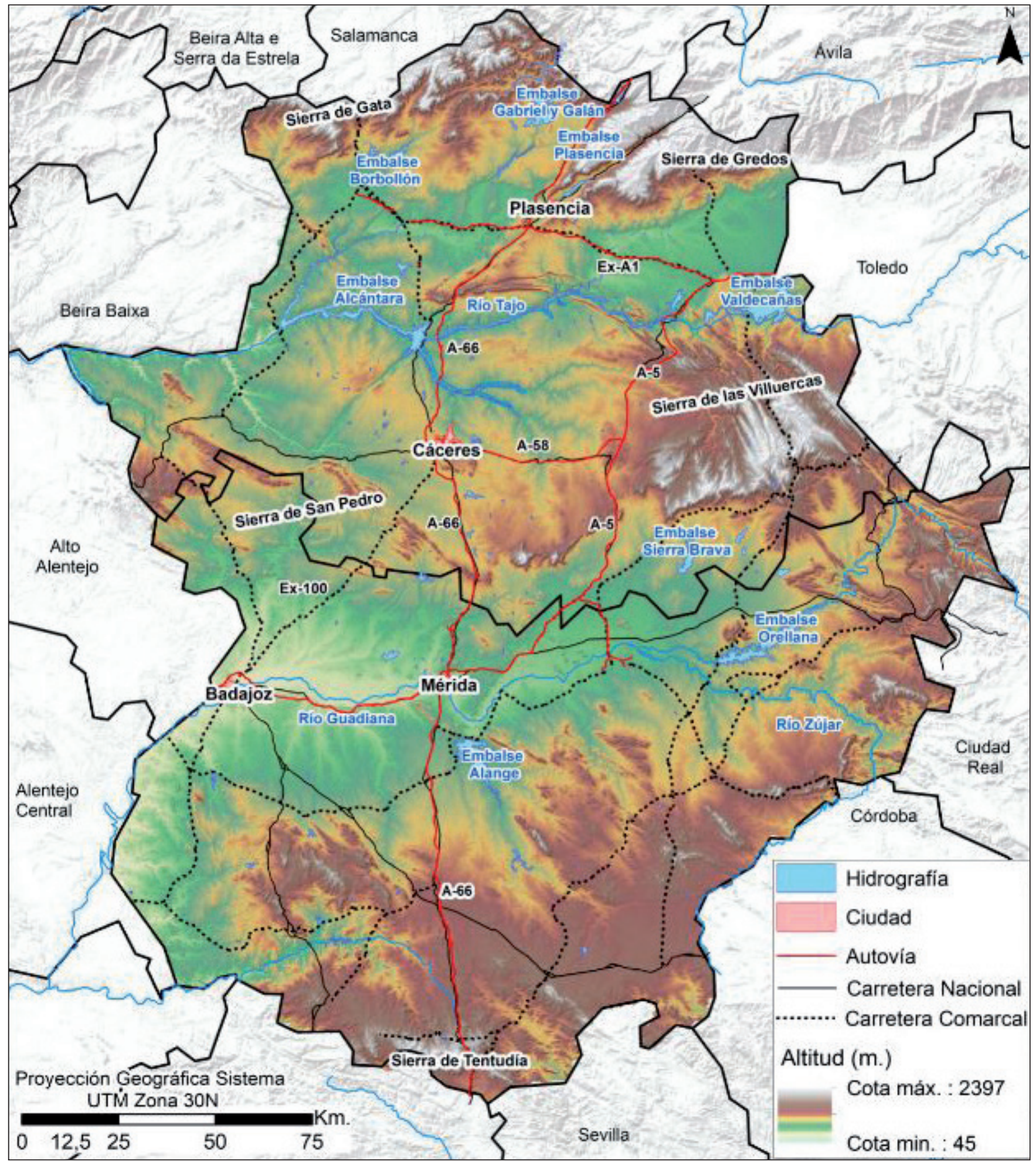

Figura 1. Área de Estudio. Fuente: Elaboración propia a través de la Base Cartográfica Nacional 1: 200.000.

mismo modo, el paso de diferentes civilizaciones por la Península Ibérica ha contribuido a incrementar el patrimonio histórico y cultural extremeño. Por citar algunos ejemplos representativos, se pueden destacar las construcciones megalíticas de Valencia de Alcántara o el Dolmen del Valle de Lácara en Mérida; la influencia de los comerciantes fenicios y griegos, como demuestran los tesoros de Aliseda (Jiménez, 2013) y Valdeobispo, así como la copa ática de Medellín (killyx). De época romana destaca la antigua capital de la Lusitania (Mérida), fundada en el 25 a.C. por el emperador Augusto para dar alojamiento a los veteranos de las guerras Cántabras (Agudo et al.,2018). Testigo de esta época se pueden citar el puente romano sobre el 
río Guadiana, el teatro, el anfiteatro o los acueductos de los Milagros y de San Lázaro. Del efímero reino visigodo se conservan pocos vestigios al haber sido reutilizados en construcciones posteriores; no obstante, en Mérida se conserva una importante colección de restos histórico-artísticos de origen germánico. Posteriormente, la extensa ocupación musulmana legará conjuntos patrimoniales tan destacables como las murallas almohades de tapial en Cáceres o de royos de río en Galisteo, sin olvidar la Alcazaba de Badajoz. Continuando, del legado cristiano encontramos la ciudad de Plasencia y los fastuosos palacios cacereños y trujillanos (muchos de ellos con la ulterior impronta renacentista). En época moderna, la crisis del siglo XVII y XVIII supondrá un cambio en los materiales de la construcción, aunque no de la monumentalidad, las yeserías barrocas del convento franciscano de Arroyo de la Luz o de la ermita de la Virgen de la Montaña en Cáceres son ejemplo de ello. De época contemporánea destacan el teatro Carolina Coronado de Almendralejo, la conocida como Casa Azul de Zafra, el Casino de Plasencia o Las Tres Campanas en Badajoz, muestras del modernismo extremeño, aunque la no incorporación de la región a la revolución industrial supuso que no se desarrollara la burguesía, clase social a la que le agradaba este tipo de construcciones (Nieto, 2014). Menos ligados al devenir histórico y más a la orografía de montaña, encontramos los pintorescos pueblos de montaña en las Hurdes, Gata, Valle del Ambroz, el Valle del Jerte y la Vera al norte de la provincia cacereña.

Todo ello integrado en un patrimonio natural en el que destacan: la Reserva de la Biosfera y Parque Nacional de Monfragüe, la Reserva de la Biosfera de la Siberia, el Geoparque Villuercas-Jara-Ibores (único ejemplo de relieve apalachense en Europa (Lagar et al., 2013)), parques naturales, monumentos naturales, paisajes protegidos, Zonas de Interés Regional (ZIR), árboles singulares, Zonas de Especial Protección para las Aves (ZEPA), Lugares de Importancia Comunitaria (LIC), entre otros. En total, casi el $40 \%$ del territorio regional está ocupado por áreas de conservación y protección de la naturaleza convirtiendo a la Comunidad Autónoma en un referente a nivel internacional.

En 2019, visitaron la región casi dos millones de personas (Observatorio de Turismo, 2020), siendo el $82 \%$ de origen nacional. El sector turístico en la región se caracteriza por su vinculación, principalmente, a las ciudades: Mérida y Cáceres, por su extenso patrimonio cultural y artístico, y Badajoz, con un turismo con mayor relación con el comercio y los negocios, y, por otro lado, el noreste de la región, ligado al turismo natural en espacio rurales. El 75,8 \% de los turistas se alojan en establecimientos hoteleros, seguido de los alojamientos rurales $(11,6 \%)$, apartamentos turísticos $(6,3 \%)$, campings $(5,3 \%)$ y, por último, los albergues $(0,7 \%)$. Los meses de máxima ocupación son julio y agosto, ligado a las tipologías de turismo rural y de naturaleza con ocupación en alojamientos rurales y campings. Seguido de los meses de marzo-abril, coincidiendo con la Semana Santa (ejemplo la Semana Santa de Cáceres declarada Fiesta de Interés Turístico Internacional) y diversas fiestas de ámbito local, algunas de ellas de difusión nacional como el Cerezo en Flor del Valle del Jerte (Fiesta de Interés Turístico Nacional). Por último, reseñar los meses octubre-noviembre con un turismo relacionado a los paisajes otoñales (Nieto et al., 2020b).

\subsection{Planeamiento metodológico para la creación del geoportal}

Los visores cartográficos son uno de los campos con mayor crecimiento dentro de los Sistemas de Información Geográfica (SIG) y prueba de ello es el gran número de aplicaciones creadas con el fin de ayudar al usuario en el desarrollo de su SIG web. Esto ha permitido que la información geográfica se utilice como herramientas productivas para la investigación y la resolución de problemas en el análisis geográfico (Buckley et al., 2000; Rodríguez-Garlito et al., 2018).

Una de las herramientas más potentes que existen en la actualidad en el mercado es ArcGIS Online de la empresa ESRI, una de las plataformas colaborativas de mapas en la nube más completa que permite al usuario crear mapas, así como compartirlos y cooperar con otros usuarios de forma gratuita (Alemy et al., 2017; Cárdenas et al.,2018). Se trata de un recurso novedoso con un gran potencial y posibilidades en la difusión de información geográfica, además de permitir su publicación de mapas de manera gratuita simplemente creando una cuenta de usuario e introduciendo las capas a publicar. 


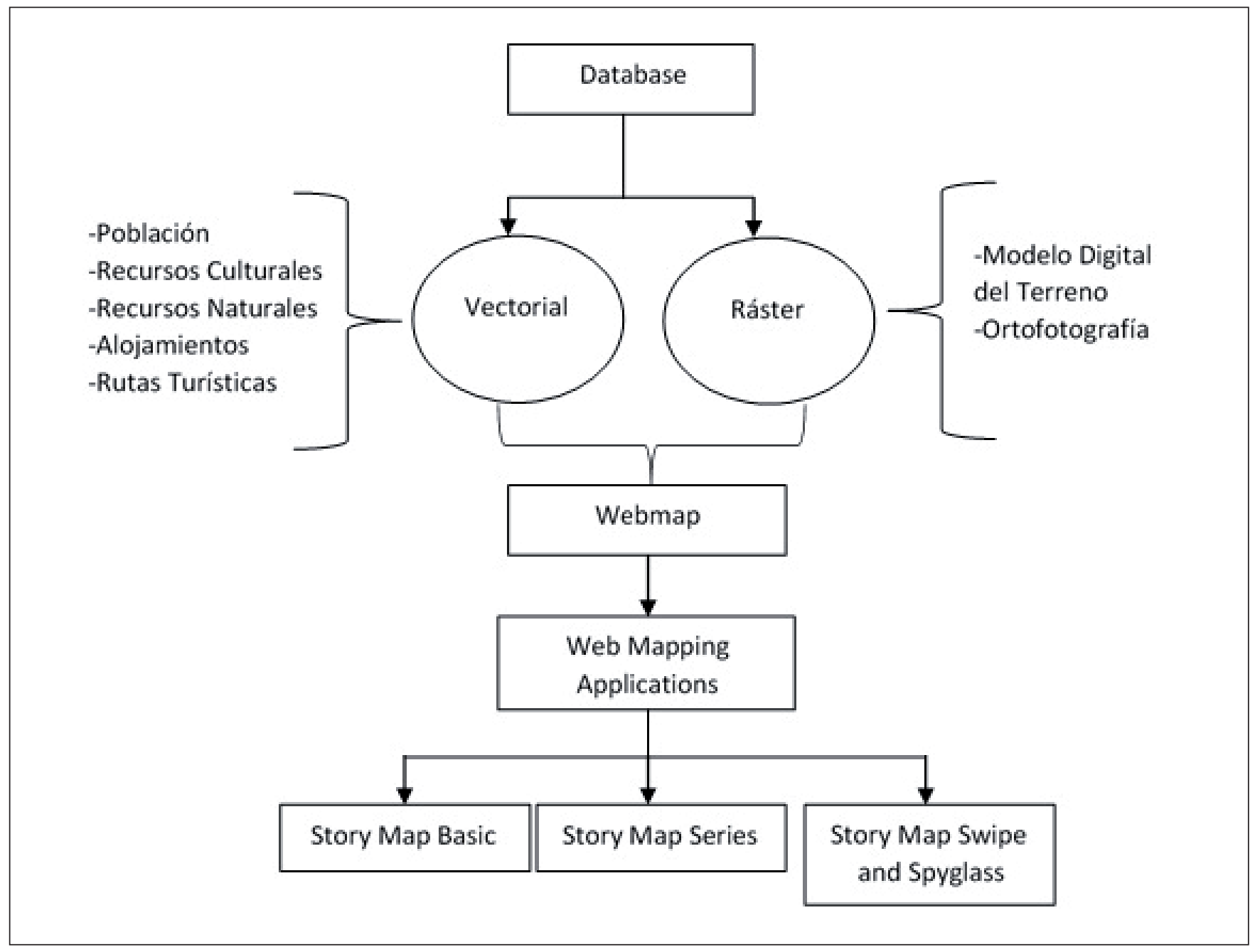

Figura 2. Diagrama del diseño del geoportal. Fuente: Autores.

Por ello, para el desarrollo del geoportal, primero se ha elaborado, en ArcMap, una base de datos cartográfica para posteriormente publicarla, por medio de mapas online, con la herramienta ArcGIS Online. Una vez introducida la base de datos cartográfica, se diseñó un geoportal con diferentes pestañas para su consulta y visualización (Figura 2). Por ello, en el siguiente subapartado se detallará la creación de la base de datos cartográfica y las características específicas de cada una de ellas en los mapas de ArcGis Online. El fin de este proyecto es presentar la herramienta y su versátil utilidad, en este caso, como medio de difusión de la oferta y los recursos turísticos en un espacio de baja densidad demográfica como es Extremadura.

\subsection{Base cartográfica}

El primer paso metodológico para el desarrollo del presente trabajo fue la construcción de la base de datos cartográfica con todas las variables necesarias para la realización del geoportal. Para lograrlo, se emplearon múltiples capas en formato shapefile, comenzando por la Base Cartográfica Nacional a escala 1:200.000 (BCN 200) del Instituto Geográfico Nacional (IGN a partir de ahora) de la que se obtuvieron los límites administrativos de los 388 municipios y de los 597 núcleos de población de la región y que sirvió como base para la construcción de la capa de puntos que contienen los alojamientos de la Comunidad Autónoma. Los datos de alojamientos fueron proporcionados por la Junta de Extremadura con información del nombre, ubicación y tipología en formato Excel. En este caso, fue necesaria la actualización y posterior georreferenciación de los más de mil cuatrocientos alojamientos. También se añadieron otras capas de información relevante para 
el turista como las vías de comunicación (carreteras y ferrocarril) obtenidas del Sistema de Información territorial de Extremadura (SITEX), un modelo digital del terreno realizado a partir de las curvas de nivel de la Base Cartográfica Nacional 1.200.000 (BCN200) para que se visualice el relieve y los principales recursos hidrográficos con la incorporación de los ríos y los embalses.

Del mismo modo, se incorporó a esta base de datos información del patrimonio cultural y de los espacios protegidos de la región. Por un lado, se añadió al patrimonio cultural la capa en formato de puntos de los Bienes de Interés Cultural (BIC), obtenida de la Junta de Extremadura, teniendo en cuenta las diferentes tipologías: Conjuntos Históricos, Monumentos, Zonas Arqueológicas, Sitios Históricos, Lugares de Interés Etnológico y la categoría de otros, con un total de 273 BIC, 118 en la provincia de Badajoz y 155 en la provincia de Cáceres. Por otro lado, una capa con los espacios protegidos de la región, donde se ha tenido en cuenta la Red Ecológica Europea Natura 2000 con 71 Zonas de Especial Protección de Aves (ZEPA) y con 89 Lugares de Importancia Comunitaria (LIC); las dos Reservas de la Biosfera: Monfragüe, y la Siberia declaradas en 2003 y 2019 respectivamente; y los Espacios Naturales Protegidos de Extremadura (RENPEX) donde destacan figuras como Parques Naturales (Cornalvo y Tajo Internacional), Reservas Naturales (Garganta de los Infiernos), Monumentos Naturales (Los Barruecos, Mina la Jayona, Cuevas de Fuentes de León o la Cueva del Castañar), Paisajes Protegidos, Zonas de Interés Regional, Árboles Singulares, etc; y por último, el Parque Nacional de Monfragüe, todo ello extraído de las bases de datos de la Junta de Extremadura.

Además, se decidió incluir, como categoría independiente en el geoportal, los enclaves catalogados como Patrimonio Mundial por la UNESCO (Organización de las Naciones Unidas para la Educación, la Ciencia y la Cultura). En Extremadura se localizan tres de los cuarenta y uno listados en España: el Centro Histórico de Cáceres, incluido en la Lista del Patrimonio Mundial en 1986, por poseer un casco histórico que alberga uno de los complejos amurallados almohades más destacados a nivel internacional; el Monasterio Real de Santa María de Guadalupe, declarado en 1993 por ser uno de los mejores ejemplos arquitectónicos religiosos de España, y el Conjunto Arqueológico de Mérida, desde 1993 como parte de los conjuntos arquitectónicos romanos mejor conservados en España. Del mismo modo, la UNESCO realiza una distinción relativa a los Geoparques por medio de una clasificación reconocida como Lista Mundial de Geoparques compuesta por un total de ciento cuarenta y siete, repartidos por algo más de cuarenta países. Aquí se incluyen trece españoles, entre ellos el Geoparque de las Villuercas, Ibores y Jara, declarado en 2011. Mencionar que se añadió también el último recurso catalogado por la UNESCO en Extremadura en 2019 la Reserva de la Biosfera de la Siberia.

También, se incorporaron los museos, archivos, centros de interpretación y oficinas de información turística extraídos del catálogo de metadatos de la Infraestructura de Datos Espaciales de Extremadura (IDEEX). La construcción de estas tipologías de recursos turísticos ha ido aumentando en los últimos años gracias a las nuevas tendencias de desarrollo endógeno que han propiciado el aprovechamiento de los recursos naturales y culturales locales fomentando el conocimiento de aspectos singulares de los territorios donde se ubican.

Por último, se añadieron los Territorios Turísticos establecidos en el Plan Turístico de Extremadura (20172020) como delimitaciones territoriales de productos y tipologías turísticas que permiten crear itinerarios globales y experiencias a medida (Junta de Extremadura, 2018).

\subsection{Diseño del Geoportal}

\subsubsection{Creación de Mapas Base en la plataforma}

Al crear la cuenta de ArcGIS Online, a través del perfil, se posibilitó el acceso a mapas, aplicaciones y herramientas publicadas por Esri y otros usuarios SIG. En este trabajo, una vez ingresado el perfil, se han ido añadiendo las diferentes capas anteriormente mencionadas en Mapas Base asignándoles un nombre y una etiqueta con el título para permitir que otros usuarios puedan encontrar también el geoportal a través de la red de ArcGis Online. También se han incluido fichas que contienen una breve descripción de todos los elementos de las capas y además se insertan fotografías para complementar la información con la intención de que los posibles usuarios que accedan al portal puedan identificar los alojamientos y los recursos de sus 
destinos de forma más sencilla. Igualmente, se ha modificado la leyenda con iconos personalizados para que aparezcan visibles en la ventana emergente.

Todos los mapas se han elaborado siguiendo el mismo procedimiento: la subida de archivos shapes o KML previamente elaborados y comprimidos por los autores del trabajo y atendiendo a sus diferentes capas de geometría como las de puntos: BIC, museos, archivos y centros de interpretación, Lugares Patrimonio de la Humanidad de la UNESCO, tesoros y oferta de alojamientos; de líneas, como vías de comunicación y ríos; y de polígonos, como los municipios, núcleos de población, espacios protegidos y territorios turísticos. Por último, las capas ráster del Modelo Digital del Terreno en formato KML.

\subsubsection{Aplicación Web de Mapas.}

Una vez configurados los Mapas Base que se integrarán en el geoportal, ArcGIS Online ofrece la posibilidad de crear aplicaciones web (Web Mapping Application) a través de plantillas disponibles de manera gratuita. Estas plantillas permiten crear diferentes combinaciones de mapas web: mapas interactivos, mapas con información 2D o 3D, añadir contenidos en formato audio, video, fotografía, etc. En este caso, se ha escogido como plantilla del geoportal, la denominada Story Map Series, que permite combinar mapas acreditados a través de pestañas, viñetas numeradas o un panel lateral con título, leyenda, imágenes, ventanas emergentes o contenido multimedia con el diseño de una interfaz atractiva y sencilla para los posibles usuarios (Figura 3).

El orden de aparición del contenido y de las diversas pestañas se ha diseñado para que aparezcan de forma lógica. Primero, dos capas generales de Extremadura y después capas relacionadas con el patrimonio, prosiguiendo con los recursos naturales, territorios turísticos, oferta de alojamientos y rutas turísticas, además de un último visor completo con todas las capas del geoportal.

Antes de presentar las capas resultantes, la aplicación parte de una breve línea de personalización, tanto de la barra que contiene las pestañas, como de los elementos que se desean mostrar. Entre otros, facilita la incorporación de una descripción, además de la asignación de contenido multimedia y enlaces web. Del mismo modo, se puede seleccionar el dejar de ver la leyenda en aquellos casos que se recojan diversidad de categorías, haciendo posible su diferenciación. En la pestaña general de Extremadura, se ha añadido una descripción con las principales características de la región.

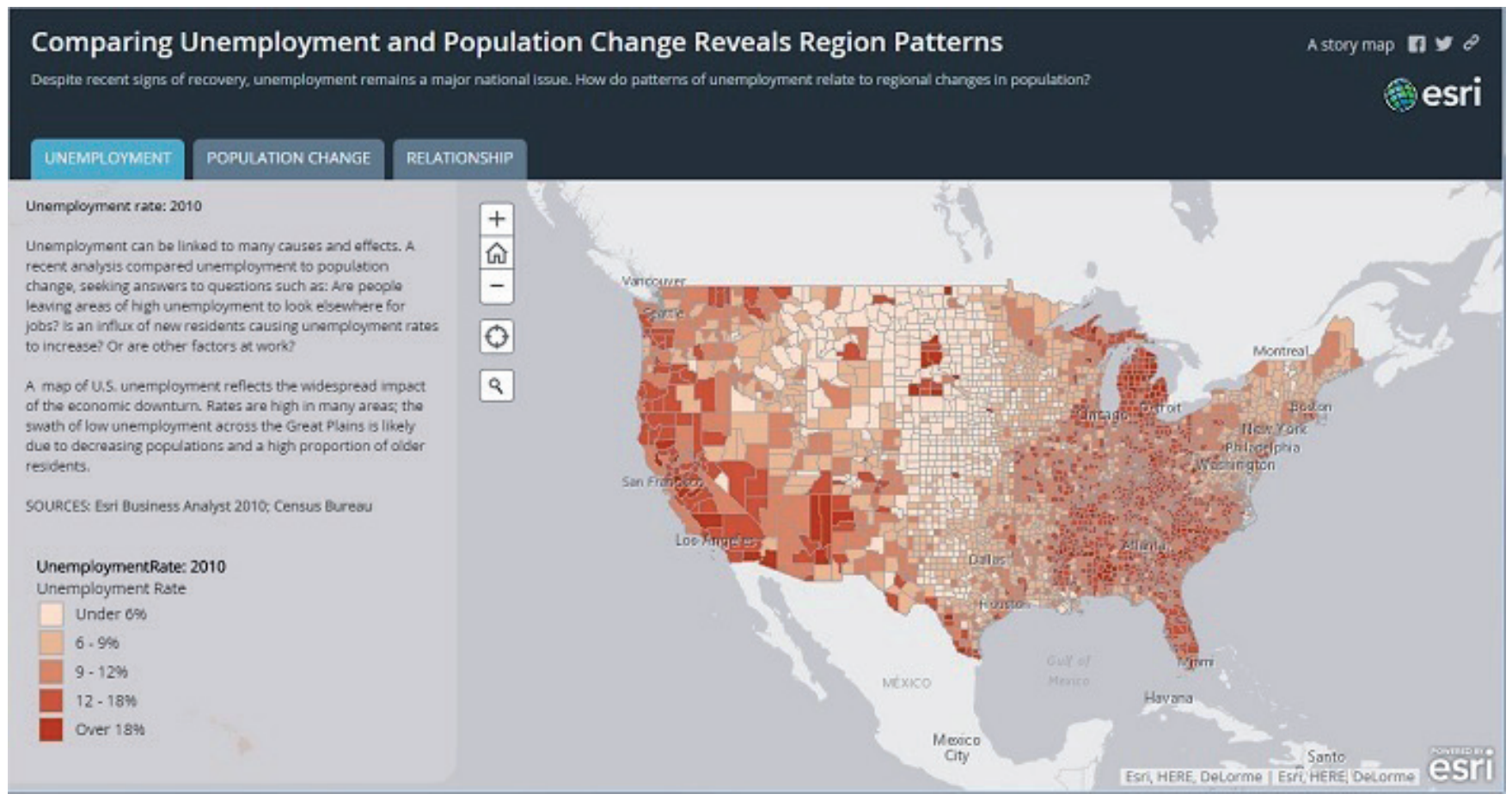

Figura 3. Story Map Series. Fuente: ArcGIS Online. 
Por último, para que pueda ser visualizado por cualquier usuario, se comparte públicamente. Al hacerlo público, el programa genera automáticamente una URL, alojada en el servidor de ArcGIS, y un código HTML que permite difundir, además de compartir el geoportal a través de cualquier plataforma de manera totalmente gratuita como Twitter o Facebook. No solamente se puede visualizar en web, sino que permite adaptarse a su consulta en móviles o tablets.

\subsubsection{Etiquetas, ventanas emergentes y leyenda}

Se han incluido en la mayoría de las capas una serie de etiquetas con la finalidad de que el usuario conozca más información acerca de la localización de los elementos. Para todas ellas se ha estipulado el mismo procedimiento, por lo que las características arrojan efectos idénticos. Respecto a su tipografía, se establece en negrita, a tamaño de once puntos y rodeadas de un halo de color blanco.

Para la elaboración de las ventanas emergentes, denominadas por ArcGIS Online como notas de mapa, se deben seguir una serie de pasos específicos que se explicarán a través de la capa designada como BIC. Partiendo de dicha capa, se inicia la búsqueda de cada uno de los municipios donde se ha declarado algún bien de interés, posteriormente, se añadieron imágenes correspondientes a cada uno de los elementos, así como la página de donde se ha extraído la información para que, una vez discernida la información en cada una de las fichas, al pulsar en la imagen se redirija al usuario al enlace establecido.

Prosiguiendo, se selecciona una entidad de puntos (en este caso una tachuela, la cual es posible modificar) a la que se pueden agregar otros sobre el elemento elegido para añadir información. Tras esto, se cambiaron las imágenes de cada una de las entidades, pues para el proyecto se han introducido símbolos propios a sazón de facilitar al usuario las diferentes opciones. Algunas de estas han sido diseñadas y añadidas a la plataforma de Google Fotos; de este modo, se obtiene un enlace, el cual se copia para añadirlo en ArcGis Online.

Como resultado final, cada BIC se compone de dos ventanas, una agrupa la información de las notas generales del elemento, en este caso el BIC que se consulta (en la Figura 4, la Iglesia de San Martín) y la segunda relativa a las características específicas de los elementos de cada capa añadida, con una descripción histórica más detallada, acompañada de una fotografía. Destacar que en la última de éstas se ha personalizado la ventana emergente, escogiendo la información deseada para que sea visible (ver Figura 4 el ejemplo de la Iglesia de San Martín).

Respecto a la leyenda, en el caso de los BIC, la capa de Museos, archivos y centros de interpretación, así como para los alojamientos turísticos, y los Lugares Patrimonio de la UNESCO ha sido necesaria la inclusión de símbolos creados especialmente para cada categoría, obtenidos de imágenes relacionadas con la infor-

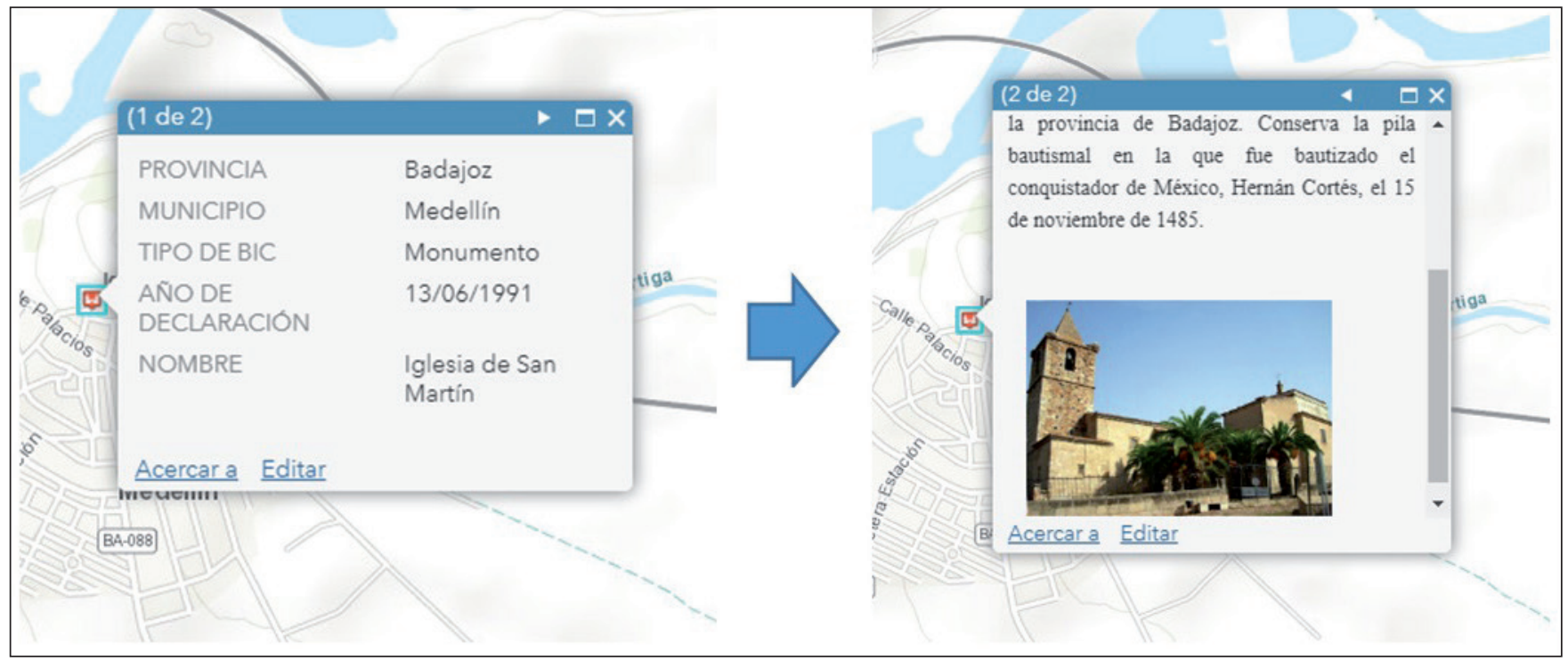

Figura 4. Ventana emergente tras la configuración (Izquierda). Descripción del BIC (Derecha). Fuente: Elaboración propia. 
mación o la identificación del recurso (por ejemplo, el símbolo de Patrimonio Cultural de la UNESCO) cuyo resultado pretende facilitar, a la par que distinguir, estos elementos con símbolos específicos, sencillos de identificar. Estas imágenes se extraen siguiendo los mismos casos que se aplicaban para las ventanas emergentes. Para la modificación de los elementos de la leyenda es necesario acceder a través de la capa, de esta manera se hace posible su transformación tocando en cada icono que se pretende cambiar.

\section{RESULTADOS}

En una sociedad cada vez más globalizada, el uso y la incorporación de las TIC es esencial, en especial en sectores como el turístico. El SIG web creado permite que los usuarios tengan una visión global del destino a visitar, pudiendo ampliar esa información a través de cada elemento incluido con una interfaz sencilla, de fácil comprensión para toda clase de usuarios y funcional en cualquier dispositivo (Smartphone, Tablet u ordenador) en tiempo real y cualquier día del año. Además, es un proyecto que nos permite estar en constante actualización añadiendo nuevos alojamientos que se hayan podido abrir o nuevos recursos a catalogar.

Tras la configuración del Story Map Series, se obtiene el resultado de este proyecto, el SIG web con las doce pestañas relativas a los mapas descritos con anterioridad y ubicadas en la parte superior y por las que el usuario puede navegar de forma libre. Cada una de ellas cuenta con una leyenda al margen izquierdo, además de una vista general del mapa base, emplazado en el lado opuesto. El resultado final (Figura 5) se puede evaluar a través del siguiente enlace: https://arcg.is/OLPuzL

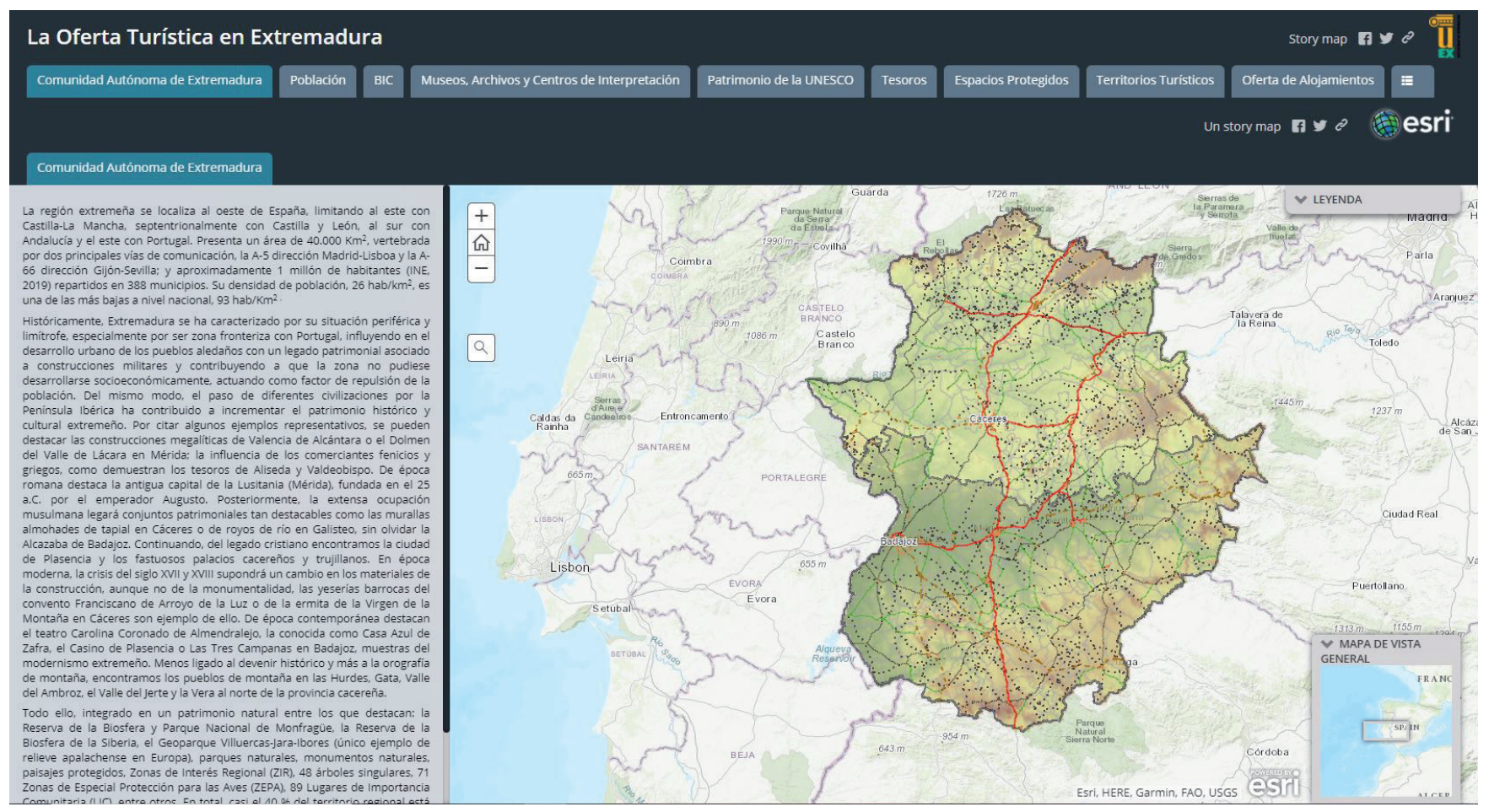

Figura 5. Vista general del geoportal “La Oferta Turística en Extremadura”. Fuente: Elaboración propia.

Como ya se ha indicado anteriormente, el geoportal se compone de doce pestañas, las dos primeras referidas a una descripción de la región, la primera titulada "Comunidad Autónoma de Extremadura" (Figura 5) y la segunda denominada "Población". Estas dos pestañas incluyen una breve información histórica de la región, la ubicación y los accesos por carreteras a los municipios, así como una radiografía actual de los datos demográficos, de esta manera el viajero tiene una primera visión general. 
A continuación, se muestran cuatro pestañas dedicadas a los recursos culturales y patrimoniales diferenciando entre los BIC (Figura 6), los Museos y Centros de Interpretación, los recursos patrimoniales de la UNESCO y los Tesoros. Estas cuatro pestañas contienen información pormenorizada de todos los recursos existentes, incluyendo: nombre del recurso, municipio en el que se sitúa, año de declaración en el caso de los recursos protegidos, información histórica e imágenes que permiten que los viajeros puedan reconocer fácilmente el recurso durante su viaje.

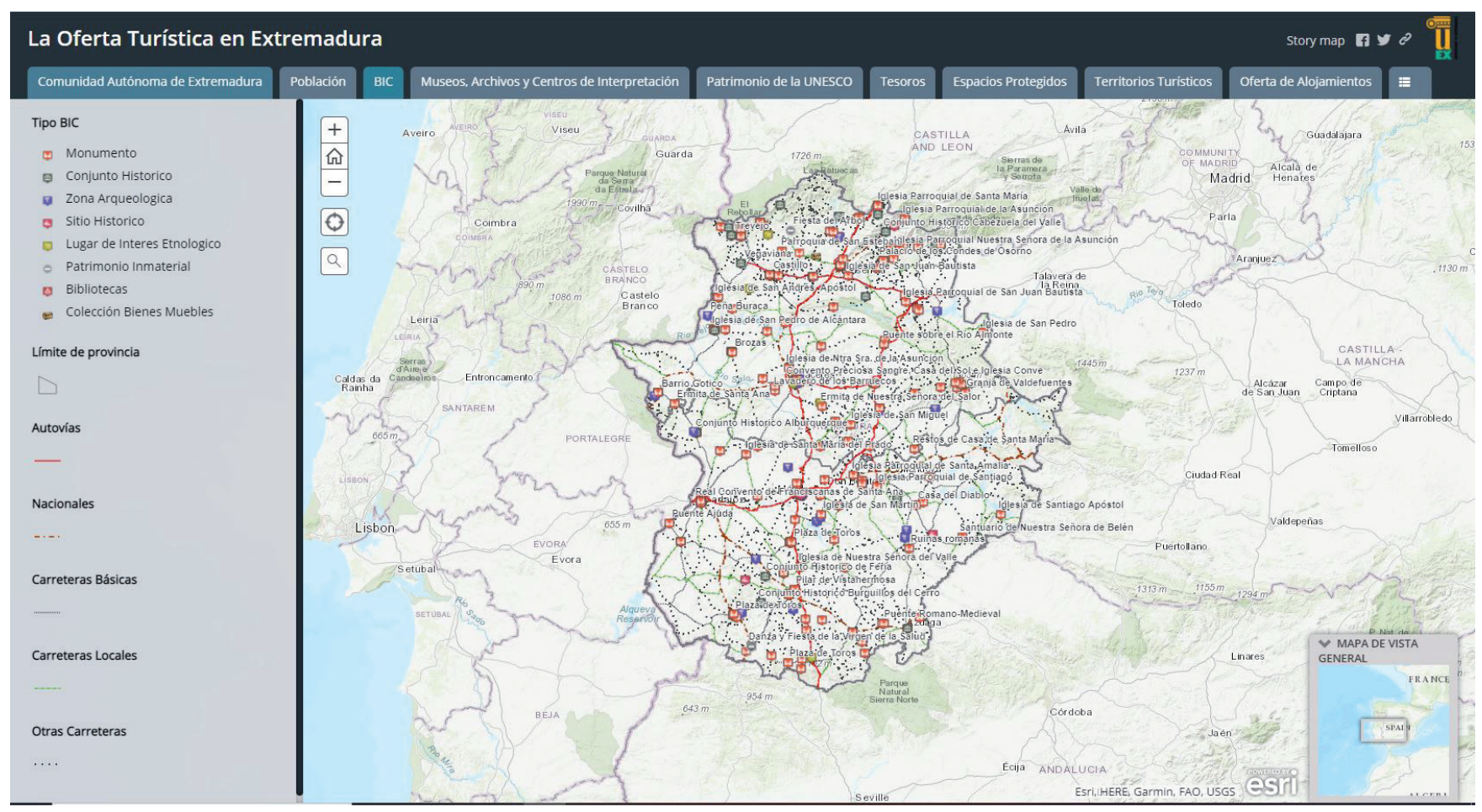

Figura 6. Geoportal "La oferta turística en Extremadura”: BIC. Fuente: Elaboración propia.

En la séptima pestaña, se ha incluido la cartografía de los espacios naturales protegidos con información básica de cada uno de ellos. La octava está dedicada a los territorios turísticos con datos de los viajeros y pernoctaciones recibidos en 2018.

Para completar la información con la oferta turística, la novena (Figura 7), denominada Oferta de Alojamientos, recoge toda la información de los mismos diferenciando entre las distintas categorías: hoteles, apartamentos, casas rurales, albergues y campings. En el caso de esta pestaña, se ha decidido incluir tanto la dirección como los números de teléfono de los alojamientos, para que el turista disponga de esta información sin necesidad de acudir a otras plataformas web.

Por último, tres pestañas más divulgativas denominadas Viajando por el tiempo, Rutas Turísticas y Recursos Extremadura. En la primera se puede realizar una comparación visual de los núcleos de población de Extremadura en los años 60 y en la actualidad (con un buscador de nombre de los municipios añadidos). La segunda contiene información sobre una de las rutas de mayor importancia en la historia de la región: La Ruta de la Plata (Figura 8), y en la última, destinada a los usuarios más avanzados en el empleo de los SIG, se ha añadido un visualizador básico en el que aparecen todas las capas y una serie de herramientas básicas como: imprimir, medir, localización o consulta (Figura 8). 


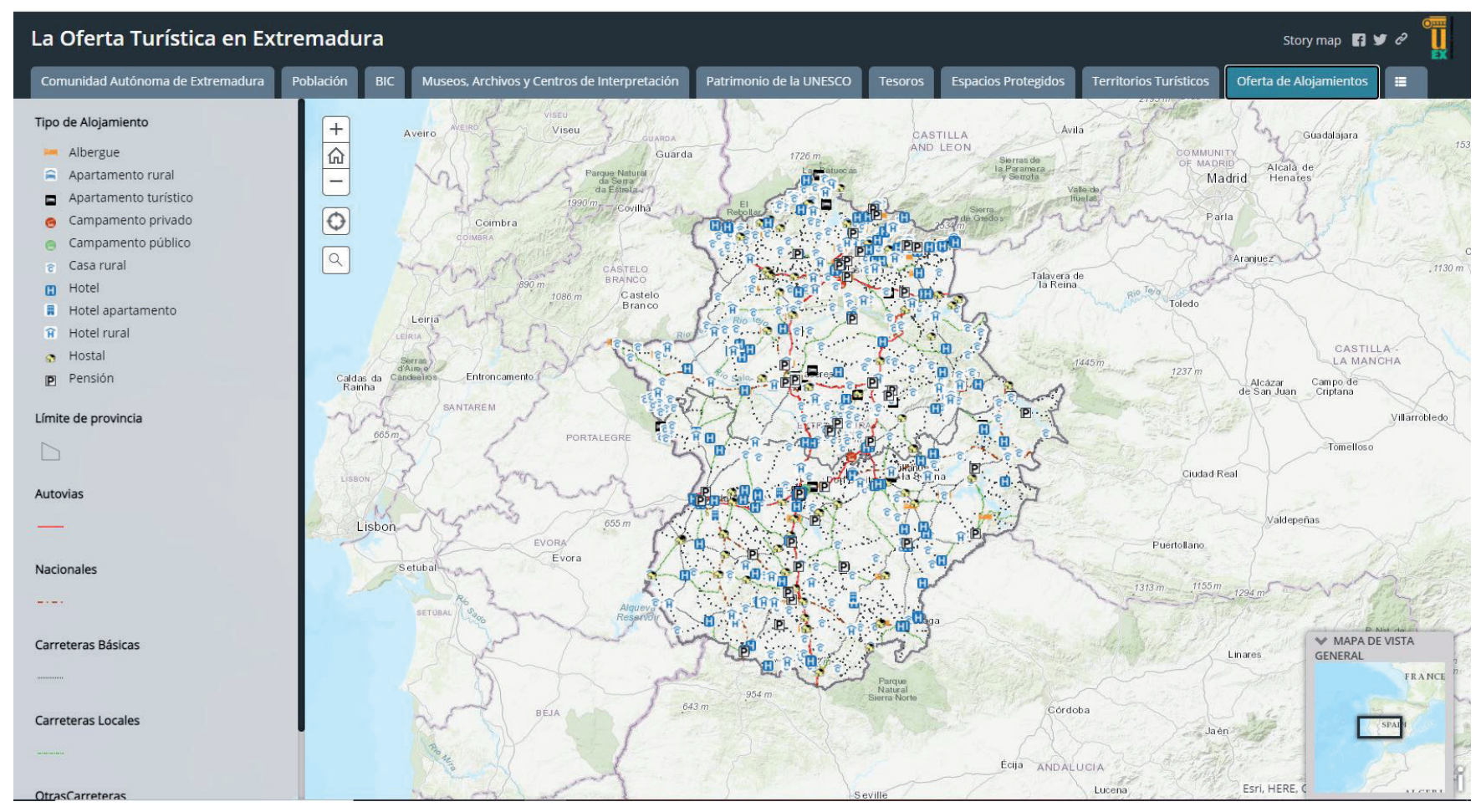

Figura 7. Geoportal “La oferta turística en Extremadura”: Oferta Alojamientos. Fuente: Elaboración propia.

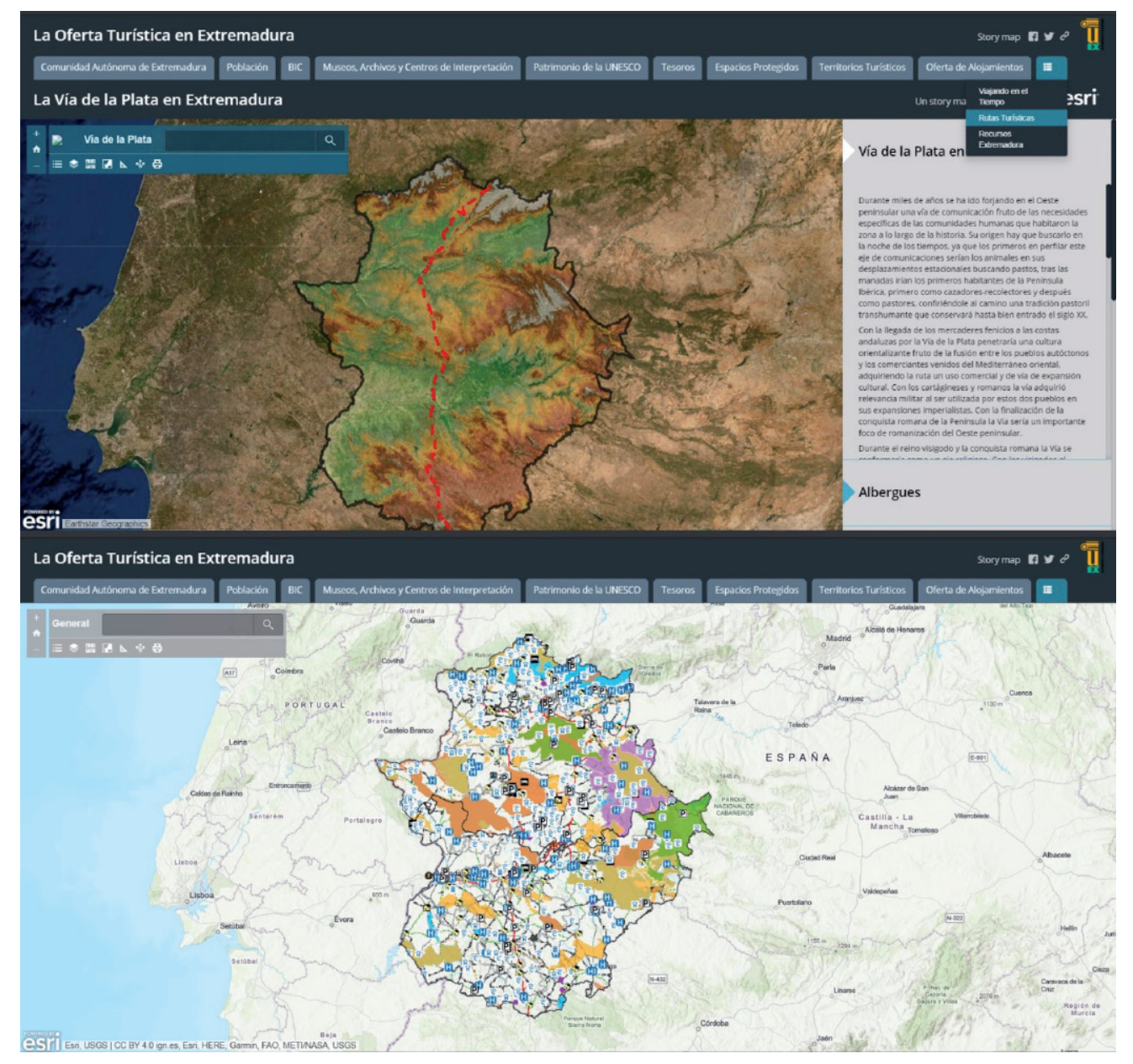
Figura 8. Geoportal "La oferta turística en Extremadura": pestañas Vía de la Plata y
Recursos Extremadura. Fuente: Elaboración propia. 


\section{DISCUSIÓN}

Los cambios en los hábitos de los turistas han permitido el desarrollo de nuevas tipologías turísticas, tales como el turismo natural, rural, patrimonial, gastronómico, etc. La incorporación de estos nuevos hábitos y la integración de las nuevas tecnologías a todos los aspectos de nuestra vida han posibilitado la creación de plataformas y geoportales que permiten a los destinos turísticos adaptarse a las nuevas demandas y diferenciarse en un mercado cada vez más competitivo y globalizado.

El desarrollo y el diseño de un SIG WEB o geoportal se ha implementado en el turismo de forma que permite a los viajeros poder conocer sus destinos mucho antes de su llegada (Bastante, 2018), además de poder seleccionar los alojamientos, las rutas, excursiones, el medio de transporte, etc. ayudados también de páginas web o blogs para consultar de forma óptima los destinos conociendo información de otros viajeros. Por ello, en el caso de este proyecto se ha creado un geoportal web para la región de Extremadura. Esta región presenta un turismo natural y cultural en auge ligado a la existencia de importantes recursos que con el cambio de paradigmas en la demanda de los turistas han ganado relevancia.

Para el desarrollo de este proyecto, se decidió utilizar el programa Arcgis Online de la empresa ESRI porque esta plataforma web permite la creación de geoportales de manera gratuita gracias a la posibilidad de añadir cartografía temática para implementarla posteriormente en aplicaciones web que obtienen como resultado páginas dinámicas e intuitivas y de fácil manejo para los posibles usuarios. Esta plataforma colaborativa permite el manejo y el uso de múltiples contenidos como son capas vectoriales, capas ráster como los Modelos Digitales del Terreno, en formato KML, implementar contenido desde la web..., con capacidad para pesadas bases de datos, como demuestra la última pestaña del geoportal que presenta información de los alojamientos existentes, de los recursos naturales, culturales y patrimoniales e información de la red de carreteras. Con el diseño de este geoportal se ha permitido difundir toda esta información turística para que el ciudadano pueda consultarla previamente a realizar su visita. Y como medio de incrementar el potencial de esta región en este sector que todavía puede generar mayores rentas económicas si se incrementan su número de viajeros y pernoctaciones (con un turismo de calidad y sin masificar).

ArcGIS Online se presenta como una de las plataformas más utilizadas actualmente (Gkatzoflias et al.,2013) aunque existen diferentes softwares que permiten la creación de SIG web o Geoportales de forma libre, como es el caso de OWGIS o ncWMS, gestores de contenido como GeoNode o framework como GeoMoose. OWGIS al igual que Arcgis Online es gratuito y presenta un gran potencial con las imágenes en 4D, sin embargo, carece de una interfaz de administración y de un motor de búsqueda de datos geográficos en la web (Gkatzoflias et al., 2013). El software ncWMS puede leer gran cantidad de formatos de datos científicos comunes, requiere una configuración mínima y proporciona a los usuarios finales un medio interactivo para visualizar datos sin necesidad de descargar archivos o interpretar metadatos, sin embargo, su uso es utilizado principalmente en el ámbito del clima y su pronóstico (Blower et al., 2013). También, destacar gestores de contenido como GeoNode (Cristofori et al., 2015) o GeoMoose (Aragão, 2020). El primero de ellos, aunque presenta ventajas como una interfaz sencilla, su instalación es complicada, y el segundo presenta un buen rendimiento, pero es necesario descargarlo e instalarlo para su uso, mientras que con ArcGIS Online se trabaja desde la red evitando así ocupar almacenaje en nuestros dispositivos.

A lo largo de este proyecto se ha hecho referencia a varios geoportales elaborados por diferentes administraciones públicas, puestos en funcionamiento con el objetivo de promocionar las diferentes potencialidades turísticas presentes en cada área, acercándolas a los posibles turistas mediante la utilización de las TIC. Por un lado, se ha aludido al geoportal del Ayuntamiento de Peñíscola que contiene información geográfica que permite a los turistas a acceder a los diferentes recursos presentes en la localidad, además de añadir herramientas para la creación de cartografía temática relacionada con las distintas producciones cinematográficas que se han realizado en la localidad, calcular rutas turísticas, compartir información en diferentes redes sociales, para lograr así un visibilidad mayor, y por último, la descarga de archivos cartográficos en distintos formatos, para acercar la experiencia al mayor número de dispositivos y usuarios posible. La interface utilizada es similar a el geoportal presentado ya que también utiliza ArcGis Online. 
El geoportal desarrollado por el Ayuntamiento de Valencia se divide en diferentes pestañas con información útil para los potenciales turistas, así como para los propios ciudadanos. Proporciona datos a tiempo real del aforo de los parkings y de las playas de la ciudad, siendo esto especialmente útil debido a las restricciones actuales de aforo derivadas de la Covid 2019. Además, permite descargar cartografía del entramado urbano y gracias a la función Story Map Swipe and Spyglass, también utilizado en el geoportal del presente proyecto, permite la comparación de los planos históricos de la ciudad con ortofotos actuales, para mostrar cómo ha afectado los cambios urbanísticos a la estructura urbana de la capital levantina. En el resto de pestañas se georreferencian las ubicaciones de edificios culturales y deportivos, el estado del tráfico, el grado de contaminación según los barrios o la localización de las oficinas de turismo. Esta información es presentada sobre un mapa base de Arcgis Online, mediante la utilización de puntos y etiquetas, de manera muy similar a las del proyecto de este estudio. Sin embargo, este geoportal no ofrece información sobre los establecimientos de alojamientos.

\section{CONCLUSIONES}

La diversidad de recursos con los que cuenta Extremadura han servido de atractivo para una nueva demanda, principalmente de personas procedentes de las grandes ciudades que buscan desconectar del estrés urbano y optan por la tranquilidad y variedad que les ofrece un turismo relacionado con el patrimonio cultural o la naturaleza, así como las actividades que puedan desarrollarse en dicho entorno frente al clásico turismo de sol y playa, cada vez más masificado que domina la oferta y el volumen de turistas que recibe España. Este auge ha favorecido a la comunidad extremeña, que ha visto incrementado el número de viajeros y pernoctaciones durante las últimas décadas. Del mismo modo, recibe turistas para realizar actividades únicas y exclusivas de ciertos entornos, como sucede con el turismo ornitológico o el gastronómico.

Por otra parte, la evolución de los Sistemas de Información Geográfica, ha permitido el perfeccionamiento de aplicaciones que abren paso a trabajar con información geográfica y hacen posible que esta sea, en ocasiones, accesible para aquellas personas que no dominan la materia. El uso de las nuevas tecnologías se ha convertido en algo indispensable en la promoción y diferenciación de cualquier destino turístico y son, actualmente, herramientas vitales para la difusión tanto del patrimonio cultural, como natural e inmaterial. ArcGIS Online se presenta como una plataforma de colaboración SIG web que permite operar datos, contenido geográfico, mapas o aplicaciones sin tener un conocimiento avanzado en SIG. De esta manera, un usuario medio puede crear su propio geoportal o geoweb con una interfaz atractiva para la difusión de un producto, de forma totalmente gratuita.

Por ello, y ante la falta de un portal web adaptado a la demanda de los turistas 3.0, este proyecto ha posibilitado la creación de un geoportal que reúne la oferta de alojamientos y recursos de Extremadura, sirviendo como medio de difusión y propaganda que puede ser actualizada continuamente. La idea de este geoportal nace de la necesidad de promoción que la Comunidad Autónoma necesita. Y es que, aunque esta región aumenta cada año el número de viajeros (en 2018 se experimentó record de visitas), el número de pernoctaciones es aún muy inferior a la media nacional, a excepción de algunos territorios como el norte de la región, que no alcanzan las dos noches por viajero. Así, el aumento de las pernoctaciones es uno de los objetivos del Plan Estratégico de Turismo 2017-2020, cuya idea es aumentarlas a través de la diversificación de las actividades y de los destinos turísticos, por lo que se consideran necesarias, para la consecución de dicho objetivo, una mayor difusión de la región y la existencia de plataformas SIG web como la creada en este trabajo a las que acceder de manera virtual en cualquier momento y desde cualquier lugar del mundo, algo esencial actualmente ante la "nueva normalidad" surgida tras la pandemia por la Covid-19.

En definitiva, en este trabajo se da a conocer cómo la inserción de las nuevas tecnologías a la industria del turismo puede producir grandes beneficios, especialmente cuando el coste económico es realmente bajo, posibilitando la diferenciación y la diversificación de los destinos turísticos. Además, con el geoportal creado se ofrece una visión en conjunto que ofrece un complejo mapa de puntos interconectados que dan a conocer y potencian la riqueza turística del territorio extremeño a fin de difundirlo más en el panorama nacional y poder incrementar tanto el número de viajeros y pernoctaciones en los próximos años y su consecuente efecto positivo en el PIB y en el empleo. 


\section{Agradecimientos}

La presentación de este trabajo ha sido posible gracias a las financiaciones concedidas por el Fondo Europeo de Desarrollo Regional de la Unión Europea y la Junta de Extremadura al grupo de investigación DESOSTE a través de la ayuda GR18052, así como también a la concesión de la ayuda para la Formación del Personal Investigador predoctoral (PD16009) de la Secretaría General de Ciencia, Tecnología e Innovación de la Junta de Extremadura

\section{Declaración responsable y conflicto de intereses}

Las autoras declaran que no existe ningún conflicto de interés con relación a la publicación de este artículo. Ángela Engelmo Moriche, Ana Nieto Masot, Ana Isabel Horcajo Romo y Gema Cárdenas Alonso concibieron y diseñaron los experimentos; realizaron los experimentos, analizaron los datos y redactaron el artículo.

\section{REFERENCIAS}

Agudo Martínez, A., Fernández Castelló, F. \& Vázquez Sánchez, G. (2018). Un caso práctico de patrimonio cultural arquitectónico europeo sin mecenazgo: el hallazgo de un nuevo templo romano en la ciudad de Mérida (Badajoz). II Congreso Internacional: Coleccionismo, mecenazgo y mercado artístico: Su proyección en Europa y América. Sevilla, Spain.

Alemy, A., Hudzik, S. \& Matthews, C. N. (2017). Creating a User-Friendly Interactive Interpretive Resource with ESRI's ArcGIS Story Map Program. Historical Archaeology, 51(2), 288-297. https://doi.org/10.1007/s41636-017-0013-7

Anato, M. (2006). El uso de los instrumentos clásicos del marketing y la tecnología digital en turismo. Estudios y perspectivas en turismo, 15(1), 19-40.

Aragão, H. G. (2020). Desenvolvimento de um sistema de informação geográfica Web (SIG Web) para a área de saneamento básico utilizando tecnologias livres. Brazilian Journal of Development, 6(2), 6835-6840. https://doi.org/10.34117/ bjdv6n2-108

Bastante Granell, V. (2018). El Turista 3.0 O Adprosumer: Un Nuevo Reto Para El Derecho Y La Economía. Revista Internacional De Derecho Del Turismo. Ridetur, 2(2), 47-73. https://doi.org/10.21071/ridetur.v2i2.11518

Blancas, F. J., Lozano-Oyola, M., González, M., Guerrero, F.M. \& Caballero, R. (2011). How to use sustainability indicators for tourism planning: The case of rural tourism in Andalusia (Spain). Science of The Total Environment, 412-413, 28-45. https://doi.org/10.1016/j.scitotenv.2011.09.066

Blower, J.D., Gemmell, A. L., Griffiths, G.H., Haines, K., Santokhee, A. \& Yang, X. (2013). A Web Map Service implementation for the visualization of multidimensional gridded environmental data. Environmental Modelling \& Software, 47, 218-224. https://doi.org/10.1016/j.envsoft.2013.04.002

Buckley, A.R., Geahegan, M. \& Clarke, K. (2000). Geographic visualizatin as an emerging reserch theme in Giscience. UCGIS.

Buhalis, D. (2012). eTourism. Information Technology for Strategic Tourism Management. Editorial Prentice Hall.

Buhalis, D. \& Law, R. (2008). Progress in information technology and tourism management: 20 years on and 10 years after the Internet-The state of eTourism research. Tourism management, 29(4), 609-623.

Buhalis, D. \& Matloka, J. (2013). Technology-enabled Tourism Destination Management and Marketing. In C. Costa, E. Panyik \& D. Buhalis (eds.), Trends in European tourism planning and organisation (pp. 339-350). Channel View Publications. https://doi.org/10.21832/9781845414122-028

Cánoves, G., Villarino, M., Priestley, G.K. \& Blanco, A. (2004). Rural tourism in Spain: an analysis of recent evolution. Geoforum, 35(6), 755-769. https://doi.org/10.1016/j.geoforum.2004.03.005

Cánoves Valiente, G., Herrera Jiménez, L. \& Villarino Pérez, M. (2005). Turismo rural en España: paisajes y usuarios, nuevos usos y nuevas visiones. Cuadernos de turismo, 15, 63-76.

Cárdenas Alonso, G. \& Nieto Masot, A. (2017). Towards rural sustainable development? Contributions of the EAFRD 2007-2013 in low demographic density territories: The case of Extremadura (SW Spain). Sustainability, 9(7), 1173. https://doi.org/10.3390/su9071173 
Cárdenas Alonso, G. \& Nieto Masot, A. (2018). Herramientas SIG Web como medio de difusión turística. En A. Nieto Masot y G. Cárdenas Alonso (Eds.), Sistema de Información geográfica y teledetección: aplicaciones en el análisis territorial (pp. 69-88). Universidad de Extremadura.

Castellano-Álvarez, F.J., del Río-Rama, M.C., Álvarez-García, J. \& Durán-Sánchez, A. (2019). Limitations of Rural Tourism as an Economic Diversification and Regional Development Instrument. The Case Study of the Region of La Vera. Sustainability, 11(12), 3309. https://doi.org/10.3390/su11123309

Capel, H. (2010). Geografía en red a comienzos del tercer milenio: para una ciencia solidaria y en colaboración. Scripta Nova, Revista Electrónica de Geografía y Ciencias Sociales, XIV (313.1). Universidad de Barcelona. http://www.ub.edu/ geocrit/sn/sn-313.htm

Cayetano Rosado, M. (2010). Fortificaciones abaluartadas de la Raya hispano-portuguesa. Revista de Estudios Extremeños, LXVI, 789-804.

Cegielska, K., Salata, T., Kudas, D. \& Szylar, M. (2018). Concept of Municipality Geoportal - Selected Legal and Administrative Issues. Geomatics and Environmental Engineering, 12(1), 45. https://doi.org/10.7494/geom.2018.12.1.45

Costantino, D., Angelini, M. G., Alfio, V.S., Claveri, M. \& Settembrini, F. (2019). Implementation of a system WebGIS open-source for the protection and sustainable management of rural heritage. Applied Geomatics, 12(1), 41-54. https://doi.org/10.1007/s12518-019-00275-6

Cristofori, E. I., Balbo, S., Camaro, W., Pasquali, P., Boccardo, P. \& Demarchi, A. (2015). Flood risk web-mapping for decision makers: A service proposal based on satellite-derived precipitation analysis and geonode. IEEE International Geoscience and Remote Sensing Symposium (IGARSS). https://doi.org/10.1109/IGARSS.2015.7326036

Elwood, S. (2009). Geographic Information Science: new geovisualization technologies — emerging questions and linkages with GIScience research. Progress in Human Geography, 33(2), 256-263. https://doi.org/10.1177/0309132508094076

García Sánchez, A. \& Alburquerque García, F. J. (2003). El Turismo cultural y el de sol y playa: ¿Sustitutivos o complementarios? Cuadernos de turismo, 11(11), 97-105. https://revistas.um.es/turismo/article/view/19581

Giuliani, G. \& Peduzzi, P. (2011). The PREVIEW Global Risk Data Platform: a geoportal to serve and share global data on risk to natural hazards. Natural Hazards and Earth System Science, 11(1), 53-66. https://doi.org/10.5194/nhess-11-53-2011

Gkatzoflias, D., Mellios, G. \& Samaras, Z. (2013). Development of a web GIS application for emissions inventory spatial allocation based on open source software tools. Computers \& Geosciences, 52, 21-33. https://doi.org/10.1016/j.cageo.2012.10.011

Godfrey, K. \& Clarke, J. (2000). The tourism development handbook: a practical approach to planning and marketing. Continuum, Vid.

Granell, C., Miralles, I., Rodríguez-Pupo, L., González-Pérez, A., Casteleyn, S., Busetto, L.,... Huerta, J. (2017). Conceptual Architecture and Service-Oriented Implementation of a Regional Geoportal for Rice Monitoring. ISPRS International Journal of Geo-Information, 6(7), 191. https://doi.org/10.3390/ijgi6070191

Gunay, A., Akcay, O. \& Altan, M. O. (2014). Building a semantic based public transportation geoportal compliant with the INSPIRE transport network data theme. Earth Science Informatics, 7(1), 25-37. https://doi.org/10.1007/s12145-013-0129-z

Hu, Y., Janowicz, K., Prasad, S. \& Gao, S. (2015). Metadata Topic Harmonization and Semantic Search for Linked-Data-Driven Geoportals: A Case Study Using ArcGIS Online. Transactions in GIS, 19(3), 398-416. https://doi.org/10.1111/tgis.12151 Instituto Nacional de Estadística (2018a). Cuenta satélite del turismo de España. https://www.ine.es/

Instituto Nacional de Estadística (2018b, 1 de abril). Estadística de Empleo Turístico según la Afiliación a la Seguridad Social. (Explotación de Turespaña) https://www.ine.es/dyngs/IOE/es/operacion.htm?numinv=16031

Instituto Nacional de Estadística. (2019). Indicadores demográficos básicos 2000-2019.

Ivars Baidal, J. A., Solsona Monzonís, F. J. \& Giner Sánchez, D. (2016). Gestión turística y tecnologías de la información y la comunicación (TIC): El nuevo enfoque de los destinos inteligentes. Documents d'Anàlisi Geogràfica, 62(2), 327. doi: 10.5565/rev/dag.285

Jiménez Ávila, J. (2013). Braseros» de bronce protohistóricos en Extremadura. Viejos y nuevos hallazgos; nuevas y viejas ideas. Revista Onoba, 01, 55-78. https://doi.org/10.33776/onoba.v0i1.1774

Junta de Extremadura (2018). Plan Turístico de Extremadura 2017-2020.

Koshkarev, A.V., Antipov, A.N., Batuyev, A.R., Yermoshin, V.V. \& Karakin, V.P. (2008). Geo-portals as part of spatial data infrastructures: Russian Academy-supported resources and geoservices. Geography and Natural Resources, 29(1), 18-27. https://doi.org/10.1016/j.gnr.2008.04.005 
Lagar Timón, D., García Marín, R. \& Pulido Fernández, M. (2013). Caracterización del potencial turístico del Geoparque Villuercas-Ibores-Jara (Extremadura, España) Investigaciones Turísticas, 5, 136-162. https://doi.org/10.14198/INTURI2013.5.06

Laguna Marín-Yaseli, M. \& Lasanta Martínez, T. (2007). Balance de las políticas públicas en el desarrollo rural del pirineo aragonés. Boletín de la A.G.E., 43, 29-49.

López-Guzmán, T., Di-Clemente, E. \& Hernández-Mogollón, J. M. (2014). Culinary tourists in the Spanish region of Extremadura, Spain. Wine Economics and Policy, 3(1), 10-18. https://doi.org/10.1016/j.wep.2014.02.002

Millán Escriche, M. (1999). El turismo rural en la planificación económica de la región de Murcia. Cuadernos de turismo, 4(4), 51-72.

Nieto Acevedo, Y. V., Romero Villalobos, O. A. \& Gallo Ramírez, K. J. (2014). Gis model of analysis to promote tourism through the use of a web application. Tecciencia, 9, 29-36. https://doi.org/10.18180/tecciencia.2014.17.4

Nieto Masot, A. (2014). Base Patrimonial. En L. F. Macorra y Cano (Ed.), Treinta años de economía y sociedad extremeña 1983-2013. Diputación de Badajoz.

Nieto Masot, A. y Cárdenas Alonso, G. (2017). 25 Años de políticas europeas en Extremadura: turismo rural y método LEADER. Cuadernos de Turismo, 39 (39), 389-416. doi: 10.6018/turismo.39.290621

Nieto Masot, A. y Cárdenas Alonso, G. (2018). The Rural Development Policy in Extremadura (SW Spain): Spatial Location Analysis of Leader Projects. ISPRS International Journal of Geo-Information, 7(2), 76. https://doi.org/10.3390/ijgi7020076

Nieto Masot, A.,Engelmo Moriche, A. Ríos Rodríguez, N. \& Cárdenas Alonso, G. C. (2020a). Análisis espacial de la oferta y demanda de alojamientos turísticos en Extremadura. En J. Escribano M.P. Peñarrubia, J.J. Serrano, S. Asins \& J. Farinós, Desafios y oportunidades de un mundo en transición: Una interpretación desde la Geografía (pp. 487-501).

Nieto Masot, A., Ríos Rodríguez, N. \& Cárdenas Alonso, G. C. (2020b). Planificación turística en Extremadura. Análisis de sus territorios turísticos. Cuadernos de Turismo 46, 291-317. https://doi.org/10.6018/turismo.451851

O'Connor, P. (1999). Electronic information distribution in tourism and hospitality. CAB international.

O'Reilly, T. (2007). What is Web 2.0? Design patterns and business models por the next generation of software. COMMUNICATIONS \& STRATEGIES, 65.

Observatorio de Turismo (2018). Boletines trimestrales de oferta y demanda. https://www.turismoextremadura.com/es/ pie/observatorio.html

Observatorio de Turismo (2020). Estudio anual de la evolución de los principales indicadores turísticos de Extremadura en 2019. https://www.turismoextremadura.com/es/pie/observatorio.html

Ojeda Zújar, J., Díaz Cuevas, P., Álvarez Francoso, J. L., Pérez Alcántara, J. P. \& Prieto Campos, A. (2015). Geoportales y geovisores web: Un nuevo entorno colaborativo para la producción, acceso y difusión de la información geográfica. In J. de la Riva, P. Ibarra, R. Montorio \& M. Rodrigues (Eds.), Análisis espacial y representación geográfica: innovación y aplicación. Universidad de Zaragoza-AGE.

Perez Fra, M.D.M. \& Lopez Ilglesias, E. (2005). La contribucion del turismo a la diversificacion de actividades en un espacio rural periferico. Analisis del impacto de la Iniciativa LEADER en Galicia. Revista Española de Estudios Agrosociales y Pesqueros, 206, 111-135. https://doi.org/10.22004/ag.econ.166075

Pillet Capdepón, F. (2016). Travellers throughout spanish landscapes: From 18th century to modern day. Cuadernos de turismo, 38, 579-576.

Reveiu, A. (2017). A web gis solution for indentifying and analysis cluester type agglomerations from tourims industry. Proceedings of the IE 2017 International Conference. Bucharest, Romania.

Rico González, M. (2005). El turismo como nueva fuente de ingresos para el medio rural de Castilla y León. Cuadernos de turismo, 16(16), 175-195.

Rodríguez-Garlito, E.C. \& Nieto Masot, A. (2018). Publicación de datos de los Bienes de Interés Cultural de la provincia de Cáceres en un Geoportal. En A. Nieto Masot y G. Cárdenas Alonso (Eds.), Sistema de Información geográfica y teledetección: aplicaciones en el análisis territoria (pp. 39-53). Universida de Extremadura.

Rodríguez Gámez, M., Vázquez Pérez, A., Sarmiento Será, A. \& Millet Ronquillo, Z. (2017). Renewable Energy Sources and Local Development. International Journal of Social Sciences and Humanities (IJSSH), 1(2), 10. https://doi.org/10.21744/ ijssh.v1i2.31

Sanagustin-Fons, V., Lafita-Cortés, T. \& Moseñe, J. (2018). Social Perception of Rural Tourism Impact: A Case Study. Sustainability, 10(2), 339. https://doi.org/10.3390/su10020339 
Sánchez Martín, J.M., Gurría Gascón, J. L., Leco Berrocal, F. \& Pérez Martín, M. N. (2001). SIG para el desarrollo turístico en los espacios rurales de Extremadura Estudios Geográficos, 62. https://doi.org/10.3989/egeogr.2001.i243.288

Sarmiento Guede, J.R. \& Ferrão Filipe, A.J. (2019). La e-experiencia de marca a través de los medios sociales y su influencia en la e-calidad de la relación y la e-fidelización. Análisis empírico en los sitios web de viajes. Cuadernos de turismo, 44, 351-380. https://doi.org/10.6018/turismo.44.404891

Sarrión-Gavilán, M.D., Benítez-Márquez, M. D. \& Mora-Rangel, E. O. (2015). Spatial distribution of tourism supply in Andalusia. Tourism Management Perspectives, 15, 29-45. https://doi.org/10.1016/j.tmp.2015.03.008

Sigala, M. \& Marinidis, D. (2012). Web map services in tourism: a framework exploring the organisational transformations and implications on business operations and models. International Journal of Business Information Systems, 9(4), 415. https://doi.org/10.1504/ijbis.2012.046293

Tu, Y., Li, Q. \& Liu, R. (2009, 12-17 July). A geospatial information portal for emergency management of natural disasters. IEEE International Geoscience and Remote Sensing Symposium. https://doi.org/10.1109/IGARSS.2009.5418100

Vizcaíno Ponferrada, M.L. (2015). Evolución del turismo en España: El turismo cultural. International Journal of Scientific Management and Tourism, 4, 75-95.

$\mathrm{Xu}$, C. (2015). Preparation of earthquake-triggered landslide inventory maps using remote sensing and GIS technologies: Principles and case studies. Geoscience Frontiers, 6(6), 825-836. https://doi.org/10.1016/j.gsf.2014.03.004

Yamashkin, S.A., RadovanoviĆ, M.M., Yamashkin, A.A., Barmin, A.N., Zanozin, V.V. \& PetroviĆ, M.D. (2019). Problems of Designing Geoportal Interfaces. GeoJournal of Tourism and Geosites, 24(1), 88-101. https://doi.org/10.30892/gtg.24108-345 